\title{
Continuous Ultrasound Assisted Sonoelectrochemical Synthesis of W-Co Alloy Nanoparticles
}

\author{
R. Plaipaité-Nalivaiko ${ }^{a, *}$, E. GrišKonis ${ }^{b}$, D. Adliené $^{c}$ And L. Gilys ${ }^{c}$ \\ ${ }^{a}$ Kaunas University of Applied Engineering Sciences, Department of Transport and Mechanical Engineering, \\ Tvirtovès al. 35, LT-50155 Kaunas, Lithuania \\ ${ }^{b}$ Kaunas University of Technology, Department of Physical and Inorganic Chemistry, \\ Radvilènų road 19, LT-50254 Kaunas, Lithuania \\ ${ }^{c}$ Kaunas University of Technology, Department of Physics, Studentų Str. 50, LT-51368 Kaunas, Lithuania \\ Tungsten-cobalt (W-Co) alloy nanoparticles have been synthesized from aqueous electrolyte by the sonoelec- \\ trochemical method applying the pulsed potential mode and continuous ultrasound irradiation. Simple electro- \\ chemical synthesis technique with the integrated ultrasonic bath (ultrasonic frequency $38 \mathrm{kHz}$, effective ultrasonic \\ power $80 \mathrm{~W}$ ) as the ultrasound source was used for this purpose. The shape and surface morphology of the synthe- \\ sized W-Co nanoparticles were determined by transmission and scanning electron microscopy, as well as composi- \\ tion of W-Co nanoparticles was assessed by energy dispersive X-ray spectroscopy. The size of synthesized W-Co \\ nanoparticles was investigated in detail by photon correlation spectroscopy. It was found that the size of produced \\ spherical W-Co nanoparticles varied from 100 to $500 \mathrm{~nm}$, and the average atomic ratio of W and Co in nanoparticles \\ was 23:4 correspondingly. The non-uniformity of synthesized particles in size and the reasons for that are discussed \\ on the basis of the obtained results.
}

DOI: 10.12693/APhysPolA.136.267

PACS/topics: 43.35.Yb, 61.05.-a, 61.46.-w, 81.07.-b

\section{Introduction}

The overwhelming attention towards nanostructured materials containing nanoparticles (NPs) is increasing day-to-day due to their exceptional size-related properties as compared to bulk materials [1-4]. Whatever they are made of, the structure, composition, and properties of nanoparticles [3,5-7] are highly important since NPs are applied in electronics, optics, catalysis, biotechnology, and medicine [8-10]. Nanosize metal [2] particles play a special role among all nanoparticles and are the most examined ones in nanotechnology. The successful application of nanoparticles depends upon both their synthesis and surface modification [1,11-13]. Surface modification can improve the intrinsic characteristics of nanoparticles and allow the fabrication of nanocomposites and other structures also non-existent in nature [14, 15]. Metal nanoparticles can be produced using well-known radiation methods [16], thermal decomposition [17], vapor deposition [18], reduction in micro emulsions [19], and chemical reduction methods [20]. Other methods are also applicable.

Specific interest is paid to the synthesis of heavy metal and alloy nanoparticles exhibiting exceptional structural, magnetic, and mechanical properties [7]. Nanocomposites containing these particles are widely used for fabrication of different hard coatings [6,21]. Also the interest

\footnotetext{
* corresponding author; e-mail: rita.plaipaite-nalivaiko@ktu.lt
}

in polymeric $\mathrm{Pb}$ free nanocomposites with incorporated heavy metal or metal alloy nanoparticles that might be used for the construction of radiation protection devices is growing up [22]. This tendency was observed during last years and is related to the EC Directive 2011/65/EU [23] which restricts application of highly toxic lead and its compounds in many areas and especially in production of electrical and electronic equipment and other devices.

It is known that pure tungsten could be produced from the corresponding salt melts only, applying electrodeposition at a high temperature and large current density [23-26]. Aqueous solutions of salts containing the iron group metals $(\mathrm{Fe}, \mathrm{Co}, \mathrm{Ni})$ are often used for this purpose [14, 21, 25-36]. Electrodeposition of tungsten is performed in a few steps. Firstly, the reduction of the tungstate(VI) ion to tungsten(IV) oxide and other complex oxygen compounds of various compositions occur. At the same time nodules of crystallites of iron group metals are formed on the electrode surface. This process is followed by reduction of tungsten oxides and their complexes to metallic tungsten and formation of tungsten alloys with $\mathrm{Fe}$, Co, or $\mathrm{Ni}[14,25,37]$. Tungsten alloys with $\mathrm{Fe}$, Co, and $\mathrm{Ni}$ can be electrodeposited from citrate, sulfamate, and pyrophosphate baths, that often contain the boric acid, and of course, key compounds-tungstate(VI) of an alkaline metal (usually sodium) and the corresponding salt of iron group metal $[4,8-10,15,26-29,36,38-44]$. According to the literature, characteristic $\mathrm{pH}$ values of these electrolytes range from 4 to 9.5 and the electrodeposition temperature using potentiostatic, galvanostatic or pulsed 
current modes varies from $25^{\circ} \mathrm{C}$ to $75^{\circ} \mathrm{C}$. The tungsten content in the electrodeposited alloys varies from a few to several tens of wt\%.

An alternative simple, fast and cost effective method is the sonoelectrochemical deposition [45]. The ultrasound $(20 \mathrm{kHz}-10 \mathrm{MHz})$ irradiated molecules in the electrolyte bath sustain a chemical reaction [46, 47] and due to the acoustic cavitation [48] participate in formation, growth, and collapse of bubbles in the liquid. The growth of the bubble occurs due to the diffusion of solute vapor into the volume of the bubble until its size reaches maximum value and the bubble collapses into smaller particles. Electrochemical synthesis of metal nanoparticles might be performed in a pulsed electrolysis mode under the assistance of continuous ultrasound radiation throughout the electrochemical deposition process, or as well under promotion of pulsed electrochemical deposition by a synchronized pulsed ultrasound mode [49].

The main advantage of the pulsed ultrasound assisted electrolysis method is that the electrochemically deposited nanoparticle shape and dimensions can be adjusted by changing the electrolyte composition and $\mathrm{pH}$ value, by changing electrolysis temperature, by varying current density and ultrasonic power, by synchronizing the current pulse duration and the operation and relaxation time of ultrasonic pulse.

The continuous ultrasound assisted electrosynthesis is another way to produce nanoparticles and to form nanostructures/nanoclusters. Under continuous ultrasound irradiation electrochemically synthesized particles grow up to their maximum size and collapse into smaller nanoparticles continuously. This process is repeated again and again until the ultrasound is switched off. In this way it is possible to get the desired size of nanoparticles or nanoclusters. The crystallinity of produced nanoparticles depends on technological (experimental) conditions [7, 11, 16, 27-30, 50].

The main purpose of this paper was to synthesize the W-Co alloy nanoparticles from the aqueous tungstate(VI)-cobalt(II) electrolyte by a simple sonoelectrochemical method of applying the continuous ultrasound and pulsed potential mode, to analyze and discuss the formation mechanism of NPs under continuous ultrasound irradiation, and to evaluate possible application of this effective technique for the low cost production of nanostructured materials.

\section{Materials, instruments, and methods}

\subsection{Electrolyte}

W-Co NPs were electrochemically synthesized in the aqueous electrolyte containing $0.05 \mathrm{M}$ of cobalt sulfate $\left(\mathrm{CoSO}_{4} \cdot 7 \mathrm{H}_{2} \mathrm{O}\right.$, Aldrich $\left.99.0 \%\right)$ and $0.2 \mathrm{M}$ of sodium tungstate $\left(\mathrm{Na}_{2} \mathrm{WO}_{4} \cdot 2 \mathrm{H}_{2} \mathrm{O}\right.$, Aldrich $\left.99.0 \%\right)$ as the source of metal species, and $0.25 \mathrm{M}$ tri-sodium citrate dehydrate $\left(\mathrm{Na}_{3} \mathrm{C}_{6} \mathrm{H}_{5} \mathrm{O}_{7} \cdot 2 \mathrm{H}_{2} \mathrm{O}\right.$, Lachema $\left.99.0 \%\right)$ as the complexing and buffering agent. $0.01 \mathrm{mM}$ of sodium dodecylsulphate $\left(\mathrm{CH}_{3}\left(\mathrm{CH}_{2}\right)_{11} \mathrm{OSO}_{3} \mathrm{Na}\right.$, Merck 99.0\%) was added to the mixture as a surfactant and stabilizer of the synthesized W-Co NPs in the electrolyte. All reagents were dissolved in doubly-distilled water with the specific conductivity of $<0.5 \mu \mathrm{S} \mathrm{cm}^{-1}$. The electrolyte prepared at room temperature was weakly alkaline $(p H=9.1)$, however, the $\mathrm{pH}$ value of the electrolyte heated up to the working temperature of $60^{\circ} \mathrm{C}$ was slightly lower i.e., 8.5.

\subsection{Sonoelectrochemical equipment and synthesis of nanoparticles}

The method of continuous ultrasound assisted sonoelectrochemical synthesis was applied for the production of W-Co NPs (Fig. 1). It is based on the application of pulsed potential mode to the working electrode under continuous impact of ultrasound waves on the electrolyte.

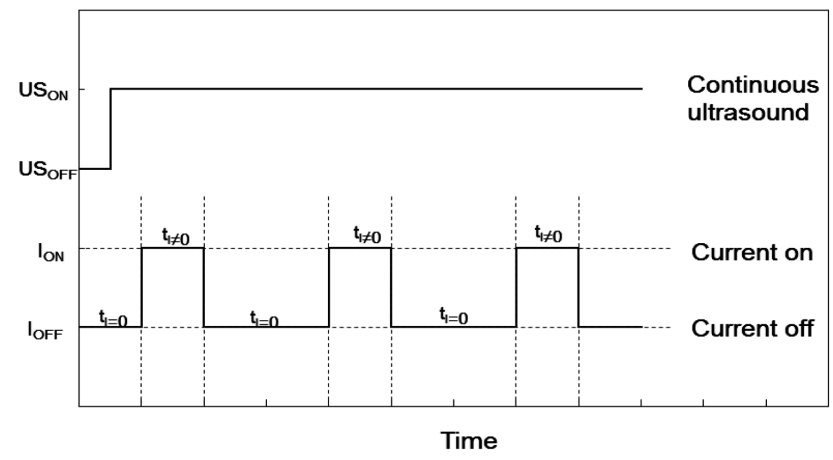

Fig. 1. Diagram of the continuous ultrasound assisted pulsed electrodeposition process.

Electrochemical synthesis of W-Co NPs was performed in the $100 \mathrm{~cm}^{3}$ volume beaker which was filled up to the half with the corresponding electrolyte. The beaker was placed into the ultrasound bath (cleaner) Sono Swiss SW3H (ultrasonic frequency $38 \mathrm{kHz}$, effective ultrasonic power $80 \mathrm{~W}$ ) keeping the same level of the electrolyte and water in the ultrasound bath (Fig. 2).

The electrolyte was heated up to the $60^{\circ} \mathrm{C}$ and this temperature was kept throughout the electrosynthesis procedure which was performed under continuous ultrasound impact. The mode of pulsed potential was maintained using the potentiostatgalvanostat SP-150 (France, BioLogic) interfaced with the EC-Lab (v10.23) software. The working electrode (cathode) was the $0.5 \mathrm{~mm}$ thick titanium alloy Ti90-Al6-V4 plate with dimensions of $3 \times 100 \mathrm{~mm}^{2}$. It was dipped by about $20 \mathrm{~mm}$ in the electrolyte during the synthesis process. Thus the working area of this electrode was approximately $140 \mathrm{~mm}^{2}$. It should be emphasized that the main reason for choosing a $\mathrm{Ti}$ alloy as a working electrode (cathode) was a poor adhesion of electrodeposits on this alloy [51]. Two square-shaped 


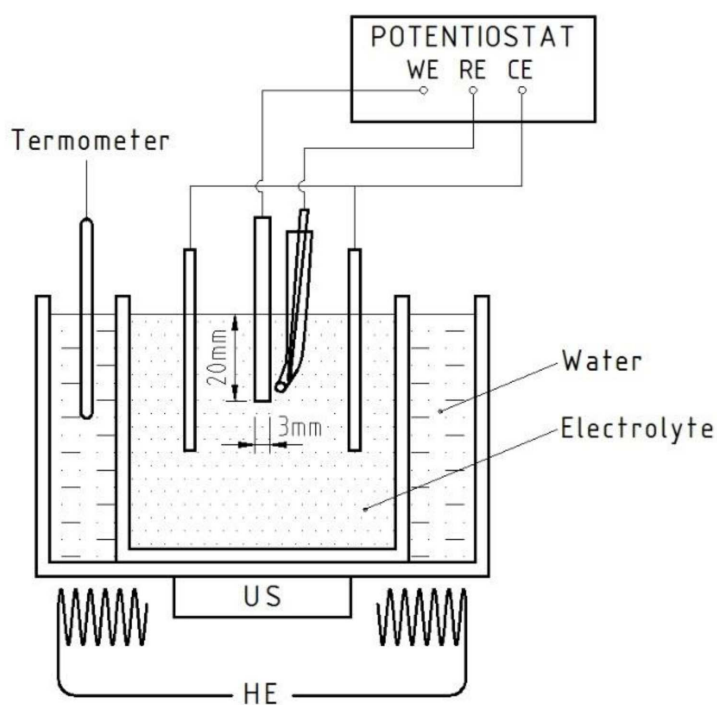

Fig. 2. Experimental setup: HE - heating coil, US - piezoelectric ultrasonic transducer, WE - working electrode, $\mathrm{E}$ - saturated $\mathrm{Ag} / \mathrm{AgCl}$ reference electrode, CE - counter (auxiliary) electrode; electrolyte containing tungstate(VI) and cobalt(II) ions.

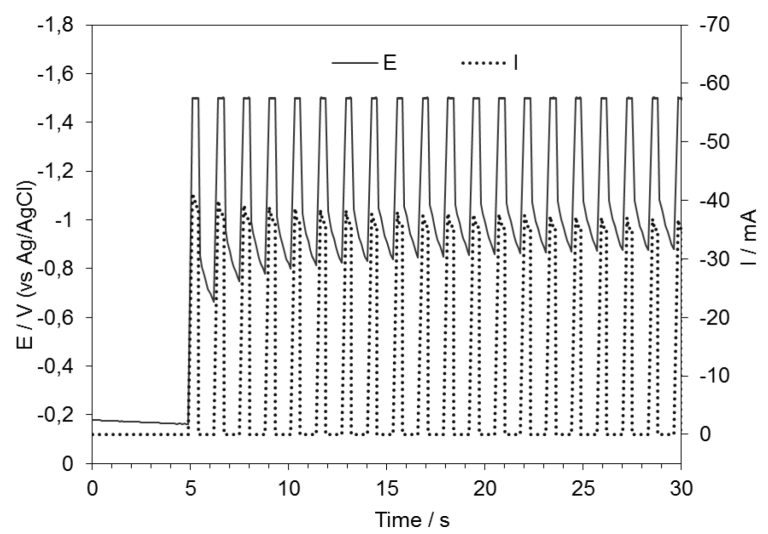

Fig. 3. Fragment of chronovoltamperometic pattern obtained during continuous ultrasound assisted pulsed electrochemical synthesis of W-Co NPs.

platinum plates with dimensions of $10 \times 10 \mathrm{~mm}^{2}$ each were symmetrically arranged on both sides of the working electrode as auxiliary electrodes (two parallel connected anodes). Before the experiment the Ti alloy working electrode surface was polished with No. 600 emery paper, washed with distilled water, and degreased with isopropanol. The potential control of the working electrode (cathode) was carried out using the saturated $\mathrm{Ag} / \mathrm{AgCl}$ electrode for reference. During the experiment the working electrode was pulse polarized from a steady-state potential of approximately $-0.16 \mathrm{~V}$ to $-1.5 \mathrm{~V}$ (vs. $\mathrm{Ag} / \mathrm{AgCl}$ ). The impulse duration was $t_{\mathrm{imp}}=500 \mathrm{~ms}$. The electrochemical system relaxed between the pulses under the open circuit conditions for $t_{\text {occ }}=800 \mathrm{~ms}$. The sonoelectrochemical synthesis in the pulsed potential mode lasted $1 \mathrm{~h}$. The fragment of chronovoltamperometric pattern is shown in Fig. 3.
Freshly synthesized W-Co NPs were transferred from the aqueous electrolyte to the trichloromethane (chloroform, $\mathrm{CHCl}_{3}$ ) solvent insoluble in water protecting them from corrosion. Transfer of $\mathrm{W}-\mathrm{Co}$ NPs was performed by centrifugation of mixture containing equal volumes of trichloromethane and electrolyte. This was possible due to the fact that the density of $\mathrm{CHCl}_{3}$ $\left(d=1.483 \mathrm{~g} / \mathrm{cm}^{3}\right)$ is higher than that of water. Centrifugation was carried out for $30 \mathrm{~min}$ in the laboratory centrifuge CL-1 at the speed $\geq 3500 \mathrm{rpm}$.

\subsection{Characterization methods of nanoparticles}

Two commercially available monochromatic lasers: red beam (wavelength, $\lambda=640 \mathrm{~nm}$, power, $N=1 \mathrm{~mW}$ ) and green beam (wavelength $\lambda=532 \mathrm{~nm}$, power $N=50 \mathrm{~mW}$ ) were used for irradiation of the electrolyte after the entire sonoelectrochemical synthesis procedure searching for the Tyndall effect which proves the presence of differently sized nanoparticles in the electrolyte. The size of synthesized W-Co NPs and distribution according to their size was investigated in detail by photon correlation spectroscopy (PCS) using the Delsa ${ }^{T M}$ Nano C (USA, Beckman Coulter) analyzer.

The morphology of W-Co NPs and their chemical composition were investigated with a scanning electron microscope (SEM, FEI Quanta 200 FEG) with the attached energy dispersive spectroscope (EDS, Bruker XFlash ${ }^{\circledR}$ 4030). The solution or, more precisely, suspension of $\mathrm{W}-\mathrm{Co}$ NPs in trichloromethane was dripped on a polished silicon wafer $(20 \mathrm{~mm} \times 20 \mathrm{~mm})$ and particles remaining on the silicon substrate after the evaporation of volatile organic solvent were analyzed. More detailed information about morphology of W-Co NPs was extracted from the transmission electron microscope (TEM, JEOL JEM 1210; maximal accelerating voltage $120 \mathrm{kV}$ ) images.

\section{Results and discussion}

\subsection{Electrochemical formation mechanism of $W-C o$ alloy}

It is known that the aqueous alkaline tungstate $\mathrm{M}_{2} \mathrm{WO}_{4}$ solution (here $\mathrm{M}=\mathrm{Li}, \mathrm{Na}, \mathrm{K}$ ) is commonly used for the tungsten electrodeposition [36, 38]. However, for the electrochemical reduction of tungstate(VI) to metallic $\mathrm{W}(0)$ up to 6 electrons there are required [36]:

$$
\begin{aligned}
& \mathrm{WO}_{4}^{2-}{ }_{(\mathrm{aq})}+8 \mathrm{H}_{(\mathrm{aq})}^{+}+6 e^{-} \rightarrow \mathrm{W}_{(\mathrm{s})}+4 \mathrm{H}_{2} \mathrm{O}_{(\mathrm{l})}, \\
& E^{0}=+0.049 \mathrm{~V} .
\end{aligned}
$$

Although the positive value of potential $E^{0}$ might lead to the theoretical assumption that the metallic tungsten should be easily electrodeposited from the aqueous solutions of salts but in practice such a large number of electrons (up to 6 electrons) in one elementary electrochemical reaction step cannot take part. Therefore tungstate reduction to metallic $\mathrm{W}$ should take place in several simple intermediate stages [38]. The first stage of electrochemical reduction of tungstate to tungsten(IV) oxide occurs in the presence of only two electrons: 


$$
\begin{aligned}
& \mathrm{WO}_{4}^{2-}{ }_{(\mathrm{aq})}+4 \mathrm{H}_{(\mathrm{aq})}^{+}+2 e^{-} \rightarrow \mathrm{WO}_{2(\mathrm{~s})}+2 \mathrm{H}_{2} \mathrm{O}_{(\mathrm{l})}, \\
& E^{0}=+0.386 \mathrm{~V} .
\end{aligned}
$$

Further tungstate reduction to metallic $\mathrm{W}$ is aggravated due to ongoing unfavourable electrochemical process - the release of gaseous hydrogen by reduction of $\mathrm{H}^{+}$ions and/or $\mathrm{H}_{2} \mathrm{O}$ molecules (depending on the electrolyte composition, temperature, $\mathrm{pH}$, etc.). The latter process results in relatively low hydrogen overvoltage values of formed tungsten-oxygen compounds on the surface. The hydrogen evolution can cause local changes in the $\mathrm{pH}$ leading to selective precipitation of some species at the growing deposit interface or induce morphological transitions and hydrogen embrittlement of the deposits.

Induced co-deposition is a well known electrodeposition mechanism of iron group metals ( $\mathrm{Fe}, \mathrm{Co}, \mathrm{Ni}$ ) and is used also for the formation of electrocoatings consisting of molybdenum and tungsten alloys. The induced co-deposition occurs when the cations of iron group metals are present in the electrolyte (in this case $\mathrm{Co}^{2+}$ ions), to form alloys of these metals (W-Co alloys) [46, 52-54]. It should be stressed that $\mathrm{Co}^{2+}$ ions are complexed with citrate $\mathrm{C}_{6} \mathrm{H}_{5} \mathrm{O}_{7}^{3-}$ ions in the electrolyte

$$
\mathrm{Co}^{2+}{ }_{(\mathrm{aq})}+\mathrm{C}_{6} \mathrm{H}_{5} \mathrm{O}_{7}^{3-}{ }_{(\mathrm{aq})} \rightarrow\left[\mathrm{Co}(\mathrm{II})\left(\mathrm{C}_{6} \mathrm{H}_{5} \mathrm{O}_{7}\right)\right]_{(\mathrm{aq})}^{-} \text {. }
$$

Taking into account the presence of this complex ion in the electrolyte, the main electrochemical reactions on the cathode are

$$
\begin{aligned}
& {\left[\mathrm{Co}(\mathrm{II})\left(\mathrm{C}_{6} \mathrm{H}_{5} \mathrm{O}_{7}\right)\right]_{(\mathrm{aq})}^{-}+e^{-} \rightarrow\left[\mathrm{Co}(\mathrm{I})\left(\mathrm{C}_{6} \mathrm{H}_{5} \mathrm{O}_{7}\right)\right]_{(\text {ads })}^{2-},} \\
& {\left[\mathrm{Co}(\mathrm{I})\left(\mathrm{C}_{6} \mathrm{H}_{5} \mathrm{O}_{7}\right)\right]_{(\text {ads })}^{2-}+e^{-} \rightarrow \mathrm{Co}_{(\mathrm{s})}+\mathrm{C}_{6} \mathrm{H}_{5} \mathrm{O}_{7}^{3-} \text { (aq) }}
\end{aligned}
$$

At the same time the reduction of tungstate(VI) ions is catalyzed by the complex particles $\left[\mathrm{Co}(\mathrm{II}) \mathrm{C}_{6} \mathrm{H}_{5} \mathrm{O}_{7}\right]^{-}$ and the following reactions occur also on the cathode:

$$
\begin{gathered}
\mathrm{WO}_{4}^{2-}{ }_{(\mathrm{aq})}+\left[\mathrm{Co}(\mathrm{II})\left(\mathrm{C}_{6} \mathrm{H}_{5} \mathrm{O}_{7}\right)\right]_{(\mathrm{ads})}^{-}+2 \mathrm{H}_{2} \mathrm{O}+2 e^{-} \rightarrow \\
{\left[\mathrm{Co}(\mathrm{II})\left(\mathrm{C}_{6} \mathrm{H}_{5} \mathrm{O}_{7}\right) \mathrm{WO}_{2}\right]_{(\mathrm{ads})}^{-}+4 \mathrm{OH}_{(\mathrm{aq})}^{-},} \\
{\left[\mathrm{Co}(\mathrm{II})\left(\mathrm{C}_{6} \mathrm{H}_{5} \mathrm{O}_{7}\right) \mathrm{WO}_{2}\right]_{(\mathrm{ads})}^{-}+2 \mathrm{H}_{2} \mathrm{O}+4 e^{-} \rightarrow} \\
\mathrm{W}_{(\mathrm{s})}+\left[\mathrm{Co}(\mathrm{II})\left(\mathrm{C}_{6} \mathrm{H}_{5} \mathrm{O}_{7}\right)\right]_{(\mathrm{aq})}^{-}+4 \mathrm{OH}_{(\mathrm{aq})}^{-} .
\end{gathered}
$$

$\mathrm{W}$ and Co atoms deposited on the cathode in this way form the $\mathrm{W}-\mathrm{Co}$ alloy. Free hydrogen is also formed at the cathode due to the side reactions taking place in the weak alkaline electrolyte

$$
2 \mathrm{H}_{2} \mathrm{O}_{(\mathrm{l})}+2 e^{-} \rightarrow \mathrm{H}_{2(\mathrm{~g})}+2 \mathrm{OH}_{(\mathrm{aq})}^{-}
$$

It should be also mentioned that the following reaction is present at the insoluble anode:

$$
4 \mathrm{OH}_{(\mathrm{aq})}^{-}-4 e^{-} \rightarrow 2 \mathrm{H}_{2} \mathrm{O}_{(l)}+\mathrm{O}_{2(g)}
$$

\subsection{Experimental formation and characterization of $W-C o N P s$}

Deposition of W-Co alloy aggregates on the cathode was performed based on the described electrochemical synthesis method under continuous assistance of ultrasound. Since an amount of free hydrogen was also present at the cathode, the ultrasound was responsible for cavitations followed by explosive collapsing of hydrogen bubbles within a very short period of time after formation, growth, and retraction. Taking into account week adhesion of electrodeposits on the surface of $\mathrm{Ti}$ and its alloys, freshly formed aggregates of $\mathrm{Co}-\mathrm{W}$ alloy, i.e. $\mathrm{Co}-\mathrm{W}$ NPs, were easily detached from the surface of Ti alloy cathode. Detached NPs were subsequently dispersed in the electrolyte bulk. Formation of W-Co aggregates was possible due to several reasons: (1) particular surface areas of Ti alloy electrode (e.g. edges and corners) may act as those with higher cathode current density where the growth of NP aggregation is promoted by each pulse of the cathode current; (2) due to different adhesion of nanoparticles in various surface areas of working Ti alloy electrode some particles formed by the cathode current are not detached from the surface of electrode under cavitation when the system operates in the open circuit mode. These particles act as nucleation centers for growing of aggregates during the following current pulses. The aggregates grow continuously until the critical mass necessary for particle detachment from the electrode surface is achieved; (3) agglomeration of individual nanoparticles to large-scale aggregates when they are transferred from the aqueous electrolyte to an organic solvent (chloroform).
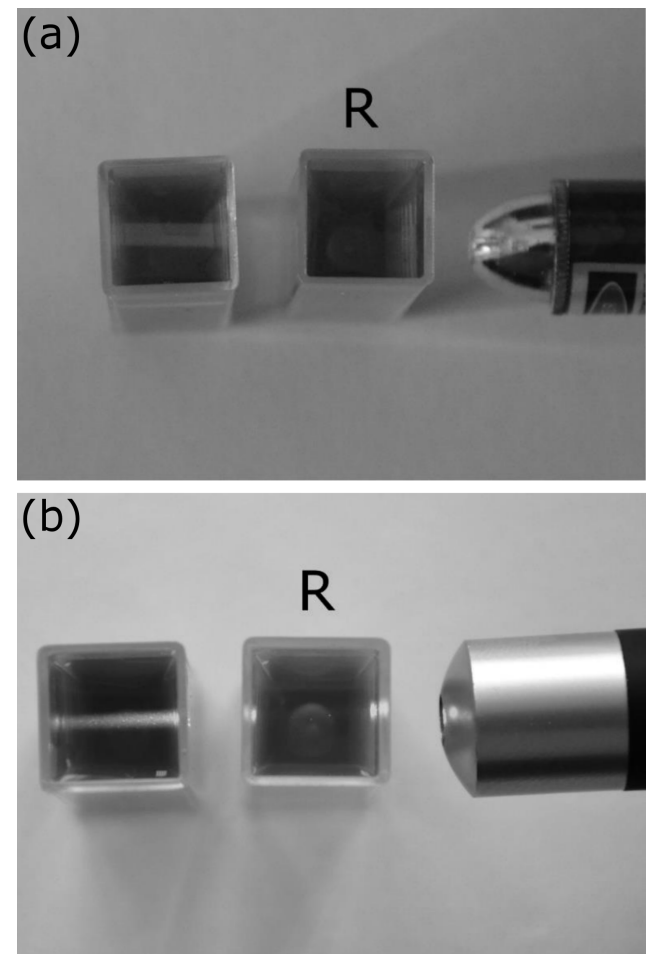

Fig. 4. Tyndall cones of scattered light in cuvettes with sonoelectrochemically synthesized $\mathrm{W}-\mathrm{Co}$ NPs dispersed in the electrolyte: (a) red laser beam $(\lambda=640 \mathrm{~nm}, 1 \mathrm{~mW})$ illumination, (b) green laser beam $(\lambda=532 \mathrm{~nm}, 50 \mathrm{~mW})$ illumination. $\mathrm{R}$ indicates reference cuvettes filled with fresh electrolyte. 
The presence of sonoelectrochemically synthesized nano/microparticles dispersed in the electrolyte was checked by passing the laser beams (red $\lambda=640 \mathrm{~nm}$ and green $\lambda=532 \mathrm{~nm}$ ) through the solution. Typical Tyndall cones of scattered light were observed in both cases (Fig. 4 and b). This phenomenon is always observed when nanosized colloidal particles are dispersed in solution. Moreover, different shapes and intensities of the Tyndall cones observed in the colloidal solution when laser beams of different wavelengths pass through it, proves the presence of differently sized W-Co NPs in it. For the comparison the reference cuvettes (indicated as $\mathrm{R}$ in Fig. 4a and b) filled with the same electrolyte before the sonoelectrochemical synthesis were illuminated by laser beams as well. No scattered light (the Tyndall cone) was observed in these cuvettes.

Once detected, the size of synthesized W-Co NPs was investigated by PCS. It was found that the particle size varied from $100 \mathrm{~nm}$ to $500 \mathrm{~nm}$. The smallest detected particle had a size of $70 \mathrm{~nm}$, and the biggest $930 \mathrm{~nm}$. The normalized distribution of the detected particles according to their size is provided in Fig. 5.

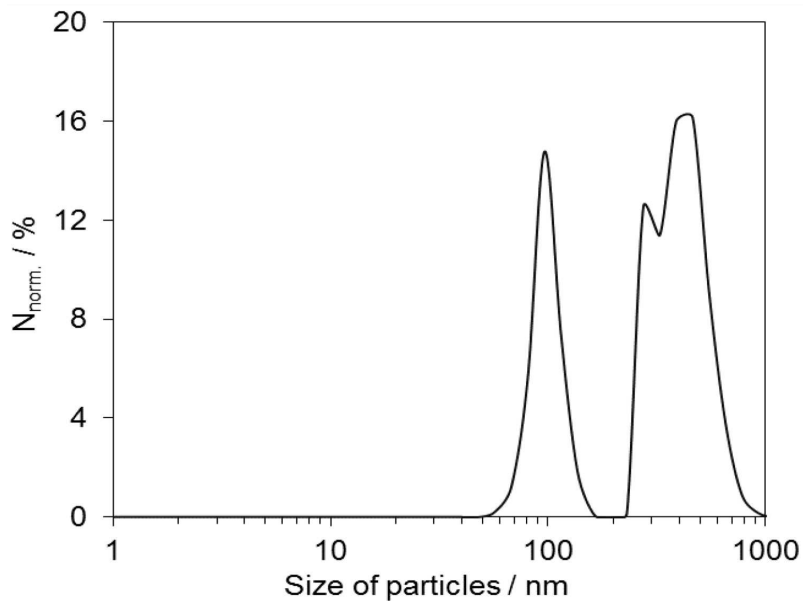

Fig. 5. Normalized distribution of sonoelectrochemically synthesized W-Co NPs.

The surface morphology of the deposited particles, and their approximate chemical composition were studied by SEM and TEM. Analyzing typical SEM and TEM images of sonoelectrically synthesized W-Co NPs (Fig. 6), it was found that despite different sizes the majority of produced particles had a spherical shape. More detailed evaluation of particle size was performed measuring a diameter of particles in several directions in the SEM and TEM images. It was found that the most frequent particles sizes were around 100, 250, and $500 \mathrm{~nm}$. However, it should be pointed out that some larger structures consisting of already aggregated nanoparticles were also observed.

The internal structure of $\mathrm{W}-\mathrm{Co}$ NPs was analyzed using TEM images. An example of the TEM image is provided in Fig. 6c where possible dispersion of Co nanoparticles within W nanoparticles could be
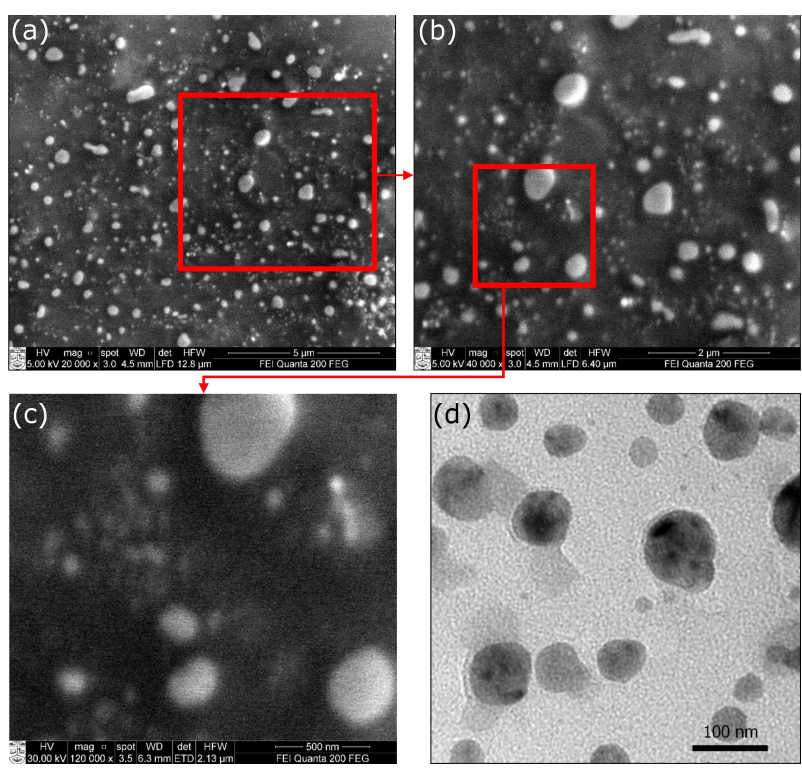

Fig. 6. SEM ((a), (b) and (c)) and TEM (d) images of synthesized W-Co NPs by continuous ultrasound assisted pulsed electrodeposition.

observed. This is related to the fact that the fraction of Co atoms in nanoparticles is much smaller than that of $\mathrm{W}$ atoms in nanoparticles. According to the performed EDS measurements the estimated atomic ratio of $\mathrm{W}$ and $\mathrm{Co}$ is 23:4. It corresponds to the tungsten content in W-Co NPs approximately of 85 at.\% as compared to 15 at.\% of cobalt. Oxidation of W-Co NPs surface was also very likely.

\section{Conclusions}

The electrochemical synthesis of nanoparticles was performed under continuous ultrasound irradiation applying the pulsed potential mode. A simple technique was used for this purpose integrating usual ultrasonic bath (cleaner) as the ultrasound source. The size of synthesized W-Co alloy nanoparticles varied from $70 \mathrm{~nm}$ to $930 \mathrm{~nm}$. However, $100 \mathrm{~nm}$ and $250 \mathrm{~nm}$ sized spherical particles were dominant. The following reasons can be related to production of non-uniform sized NPs: (1) nonuniform growth rate of nanoparticles on different surface areas of Ti alloy cathode; (2) non-uniform adhesion of particles on the cathode due to its surface inhomogeneity which is related to non-uniform detachment of formed particles from the cathode surface when continuous ultrasound is applied and growth of remaining on the cathode surface NPs to the larger aggregates during the following cathode current pulses; (3) the agglomeration of smaller particles to larger aggregates during their transfer from the aqueous electrolyte to an organic solvent. The estimated atomic concentrations of $\mathrm{W}$ and Co in NPs were 85 at.\% and 15 at.\%, respectively, and this corresponds to their atomic ratio 23:4. Despite the work which 
should be done by increasing the uniformity of synthesized NPs, the discussed sonoelectrochemical synthesis method can be used for simple and cost effective production of $\mathrm{W}-\mathrm{Co}$ alloy nanoparticles.

\section{Acknowledgments}

This research was funded by the Research Council of Lithuania (grant No. MIP-091/2012) as a part of the ongoing project "Optically transparent polymeric nanocomposite shields for radiation protection".

\section{References}

[1] A. Gedanken, Ultrason. Sonochem. 11, 47 (2004).

[2] V. Sáez, T.J. Mason, Molecules 14, 4284 (2009).

[3] P. Indyka, E. Beltowska-Lehman, L. Tarkowski, A. Bigos, E. Garcia-Lecina, J. Alloy Comp. 590, 75 (2014).

[4] H. Cesiulis, A. Baltutiene, M. Donten, M.L. Donten, Z. Stojek, J. Solid State Electrochem. 2, 237 (2002).

[5] M.P. Quiroga Arganaraz, S.B. Ribotta, M.E. Folquer, E. Zelaya, C. Llorente, J. Ramallo-López, G. Benitez, A. Rubert, L. Gassa, M. Vela, R. Salvarezza, Electrochim. Acta 72, 87 (2012).

[6] N. Tsyntsaru, H. Cesiulis, A. Budreika, X. Ye, R. Juskenas, J.P. Celis, Surf. Coat. Technol. 206, 4262 (2012).

[7] N. Tsyntsaru, H. Cesiulis, E. Pellicer, J.P. Celis, J. Sort, Electrochim. Acta 104, 94 (2013).

[8] J. Puiso, J. Laurikaitiene, D. Adliene, Radiat. Protect. Dosim. 139, 353 (2010).

[9] A. Bodaghi, J. Hosseini, Int. J. Electrochem. Sci. 7, 2584 (2012).

[10] A.S.M.A. Haseeb, K. Bade, Microsyst. Technol. 14, 379 (2008).

[11] Ma. Miaomiao, V.S. Donepudi, G. Sandi, Y.K. Sun, J. Prakash, Electrochim. Acta 49, 4411 (2004).

[12] V. Mancier, A.L. Daltin, D. Leclercq, Ultrason. Sonochem. 15, 157 (2008).

[13] V. Mancier, C. Rousse-Bertrand, J. Dille, J. Michel, P. Fricoteaux, Ultrason. Sonochem. 17, 690 (2010).

[14] M. Donten, Z. Stojek, H. Cesiulis, J. Electrochem. Soc. 150, 95 (2003).

[15] M. Donten, H. Cesiulis, Z. Stojek, Electrochim. Acta 50, 1405 (2005).

[16] M.S. Yeh, Y.S. Yang, Y.P. Lee, H.F. Lee, Y.H. Yeh, C.S. Yeh, J. Phys. Chem. B 103, 6851 (1999).

[17] Y.H. Kim, D.K. Lee, B.G. Jo, J.H. Jeong, Y.S. Kang, Coll. Surf. A 284, 364 (2006).

[18] A.A. Ponce, K.J. Klabunde, J. Mol. Catal. A Chem. 225, 1 (2005).

[19] S.K. Haram, A.R. Mahadeshwar, S.G. Dixit, J. Phys. Chem. 100, 5868 (1996).

[20] A.A. Athawale, P.P. Katre, M. Kumar, M.B. Majumdar, Mater. Chem. Phys. 91, 2, 507 (2005).

[21] N. Tsyntsaru, H. Cesiulis, M. Donten, J. Sort, E. Pellicer, E.J. Podlaha-Murphy, Surf. Eng. Appl. Electrochem. 48, 491 (2012).
[22] L. Gilys, D. Adliene, E. Griskonis, InterAcademia LNNS 53, Springer Nature Switzerland AG 2019, 2019, p. 144.

[23] Directive 2011/65/ EU of the EU Parliament and of the Council, 8 June 2011, on the restriction of the use of certain hazardous substances in electrical and electronic equipment, OJ L 174 1.7.2011, p. 88.

[24] D. Adliene, E. Griskonis, N. Vaiciunaite, Radiat. Protect. Dosim. 165, 406 (2015).

[25] K. Nitta, Sh. Inazawa, K. Okada, H. Nakajima, T. Nohira, R. Hagiwara, Electrochim. Acta 53, 20 (2007).

[26] N.I. Tsyntsaru, S.S. Belevskii, G.F. Volodina, O.L. Bersirova, Y.S. Yapontseva, U.S. Kublanovskii, A.I. Dikusar, Surf. Eng. Appl. Electrochem. 43, 312 (2007).

[27] M. Donten, T. Gromulski, Z. Stojek, J. Alloys Comp. 279, 272 (1998).

[28] Zh.I. Bobanova, W.I. Petrenko, S.A. Silkin, S.P. Yushchenko, E.A. Yakhova, Elektronnaya obrabotka materialov 41(6), 86 (2005) (in Russian).

[29] S.A. Silkin, O.V. Tin'kov, W.I. Petrenko, N.I. Tsyntsaru, A.I. Dikusar, Elektronnaya obrabotka materialov 42(4), 11 (2006) (in Russian).

[30] M. Donten, H. Cesiulis, Z. Stojek, Electrochim. Acta 45, 3389 (2000).

[31] K.B. Kushkhov, M.N. Adamokova, Russ. J. Electrochem. 43, 997 (2007).

[32] A. Brenner, Electrodeposition of Alloys 2, Academic Press, New York 1963.

[33] V. Vasauskas, J. Padgurskas, R. Rukuiža, H. Cesiulis, J.P. Celis, D. Milčius, I. Prosyčevas, Mechanika 4, 21 (2008).

[34] Z.A. Hamid, Mater. Lett. 57, 2558 (2003).

[35] A. Subramanian, G.N. Kousalya, V.S. Muralidharan, T. Vasudevan, Indian J. Chem. Techn. 9, 513 (2002).

[36] A. Brenner, P. Burkhead, E. Seegmiller, Research Paper RPI1834 39, 351 (1947).

[37] Z.J. Niu, S.B. You, S.M. Zhou, J. Electroanal. Chem. 455, 205 (1998).

[38] A. Krohn, T.M. Brown, J. Electrochem. Soc. 108, 60 (1961).

[39] E. Gomez, E. Pellicer, E. Valles, J. Electroanal. Chem. 517, 109 (2001).

[40] E. Pellicer, E. Valles, Surf. Coat. Technol. 197, 238 (2005).

[41] E. Gomez, E. Pellicer, X. Alcobe, E. Valles, J. Solid State Electrochem. 8, 497 (2004).

[42] E. Gomez, E. Pellicer, E. Valles, J. Electroanal. Chem. 580, 222 (2005).

[43] N.I. Tsyntsaru, T.S. Eagleton, L.G. Earwaker, J.P.G. Farr, I.P. Jones, Trans. IMF 85, 34 (2007).

[44] N. Eliaz, T.M. Sridhar, E. Gileadi, Electrochim. Acta 50, 2893 (2005).

[45] V. Zin, B.G. Pollet, M. Dabala, Electrochim. Acta 54, 7201 (2009).

[46] J. González-García, M.D. Esclapez, P. Bonete, Y.V. Hernandez, L. Gaete Garreton, V. Sáez, Ultrasonics 50, 318 (2010). 
[47] D.J. Walton, ARKIVOC 3, 198 (2002).

[48] J. Klima, Ultrasonics 51, 202 (2011).

[49] S.M. Delphine, M. Jayachandran, C. Sanjeeviraja, Mater. Chem. Phys. 81, 78 (2003).

[50] H. Cesiulis, A. Baltutiene, M. Donten, M.L. Donten, Z. Stojek, J. Solid State Electrochem. 6, 237 (2002).

[51] M.J. Donachie, Titanium: A Technical Guide, 2nd ed., ASM International, 2000, p. 381.
[52] S.S. Belevskii, H. Cesiulis, N.I. Tsyntsaru, A.I. Dikusar, Surf. Eng. Appl. Electrochem. 46, 570 (2010).

[53] E.J. Podlaha, D. Landolt, J. Electrochem. Soc. 143 , 893 (1996).

[54] E.J. Podlaha, D. Landolt, J. Electrochem. Soc. 144, 1672 (1997) 